\title{
Life-cycle Water Quantity and Water Quality Implications of Biofuels
}

\author{
May Wu $\cdot$ Zhonglong Zhang $\cdot$ Yi-wen Chiu
}

Published online: 11 February 2014

(C) Springer International Publishing AG 2014

\begin{abstract}
Water consumption and water quality continue to be key factors affecting environmental sustainability in biofuel production. This review covers the findings from biofuel water analyses published over the past 2 years to underscore the progress made, and to highlight advancements in understanding the interactions among increased production and water demand, water resource availability, and potential changes in water quality. We focus on two key areas: water footprint assessment and watershed modeling. Results revealed that miscanthus-, switchgrass-, and forest wood-based biofuels all have promising blue and grey water footprints. Alternative water resources have been explored for algae production, and challenges remain. A most noticeable improvement in the analysis of life-cycle water consumption is the adoption of geospatial analysis and watershed modeling to generate a spatially explicit water footprint at a finer scale (e.g., multi-state region, state, and county scales) to address the impacts of land use change and climate on the water footprint in a landscape with a mixed biofuel feedstock.
\end{abstract}

Keywords Biofuels · Climate $\cdot$ Landscape management Life-cycle water use $\cdot$ Nitrogen $\cdot$ Phosphorus $\cdot$ Suspended sediments · Water consumption · Water footprint $\cdot$ Water quality $\cdot$ Watershed modeling

\section{Wu $(\bowtie) \cdot$ Y.-w. Chiu}

Argonne National Laboratory, 9700 S. Cass Avenue, Lemont, IL, USA

e-mail: mwu@anl.gov

Y.-w. Chiu

e-mail: yiwen.chiu@gmail.com

\section{Z. Zhang}

Badger Technical Services, US Army Corps of Engineers,

Engineer Research and Development Center,

Environmental Laboratory, Vicksburg, MS, USA

e-mail: zhonglong.zhang@erdc.dren.mil

\author{
Abbreviation \\ CS corn-soybean \\ ET evapotranspiration \\ GAEZ Global Agro-Ecological Zones \\ GIS geographic information systems \\ LCA life-cycle analysis \\ LUC land use change \\ MWW municipal wastewater \\ SRWC short rotation woody crop \\ SWAT Soil and Water Assessment Tool \\ SWG Switchgrass \\ UMRB Upper Mississippi River Basin \\ WUE water use efficiency
}

\section{Introduction}

Over the past 2 years, there has been a growing body of literature examining the environmental and economic sustainability of unconventional fuels. Among them, articles on biofuels and shale gas production dominate the published studies. Although the life-cycle greenhouse gas emission benefits of using biofuels have been well-documented over the past two decades, the life-cycle impact of biofuel production on water resource use and water quality remains less clear because of the complexity of the biofuel production system worldwide [1-6]. Studies have shown that water use for the production of biofuel depends on the feedstock and production technology and is highly influenced by regional climate and environmental conditions. Therefore, technology advancement, regional variability, and the nature of feedstocks can all affect the assessment of life-cycle water consumption. This is especially true for new feedstocks and conversion pathways that are in an early stage of research and development, such as algae, jatropha, and perennial grasses. 
In the past 2 years, researchers have conducted a number of studies that focused on the water footprint of new feedstocks $[1,7,8 \bullet \bullet, 9 \bullet, 10-18]$, which is an increasingly important issue. Among them, about $40 \%$ of the studies concentrated on cellulosic feedstocks and $30 \%$ focused on algae and oil seed crops. The remaining one-third of the studies addressed grain and sugar crops. The major cellulosic feedstocks of interest appear to be switchgrass and miscanthus. Hydrologic models and tools have been employed to provide spatial and temporal information to be used in estimates of life-cycle water use. The application of watershed modeling to estimate the impacts of changes in future land use on water quality due to projected feedstock production and under climate change has increased significantly $[19-24,25 \cdot, 26]$, and the focus of modeling has been on (1) the Midwest because it has vast amounts of corn stover available, and (2) the southeast coastal plain and northeast region because they have the large potential to produce fastgrowing energy crops.

The purpose for the review was to assess the progress made to quantify life-cycle water consumption in the production of biofuels, especially advanced biofuels. We focus on two major areas - water footprint assessment and watershed modeling and cover the literature on biofuels that has been published in the past 2 years. Results from recent assessments of life-cycle water consumption are summarized and compared. Trends, uncertainties, and future needs are presented.

\section{Models and Analysis Tools}

With its extensive agricultural dataset for land management and cropping practices, the Soil and Water Assessment Tool (SWAT) model remains a widely adopted tool for simulating the influences of land use change on water quality under current and future biofuel scenarios [19, 21, 22, 25•, 27]. Researchers are extending watershed analysis to address other aspects of biofuel production (such as climate change, landscape management and agricultural practices, and production economics) by incorporating other models and tools, which allows analysis of interactions among various components within the production system and the environment, and enables the option of factoring in spatial and temporal parameters. Climate change projections were applied by using SWAT [27, 28 •]. SWAT output was used in an adaptive, neural-fuzzy inference system (ANFIS) to simulate streamhealth sensitivity to land use change (LUC) [26]. SWATDaycent was used to optimize production options by using a multi-objective approach [25•]. Groundwater vulnerability under LUC in North Dakota was examined by using integrated models [29]. Other approaches rely on ecosystem and economic models, such as the ecosystem model TEM and the Integrated Biosphere Simulator model (Agro-IBIS) [13, 14], the GIS model [11], GTAP-BIO [30], and the use of an agro-economic model and climate model in sequence [31].
From a life-cycle perspective, water footprint accounting has been demonstrated to be valuable in providing a spatially explicit water resource use assessment for biofuel production pathways [1, $7,8 \bullet \bullet, 9 \bullet, 10,12,15,18]$. A water footprint framework employs SWAT to enhance grey water assessment [8••]. CROPWAT and Global Agro-Ecological Zones (GAEZ) have been used in green and blue water estimates for crops [12, 18], while the Hargrievz method was preferred for US conditions [7]. The variability of the water footprint under various climate conditions has been analyzed [24]. BASINS and EPIC have been incorporated into lifecycle analysis through a framework WORLD [32••]. A multiobjective, mixed-integer, linear programming model has been applied to evaluate the economics and the carbon and water footprint of bioethanol supply chains [33]. USEtox [34] and the ecological damage index [35] were proposed to quantify the lifecycle impact of increased biofuel production on freshwater ecology. Water stress index remains the dominant parameter used to measure water resource availability [1].

\section{Life-cycle Water Consumption}

\section{a. Green, blue, and grey water footprint}

Significant progress has been made in developing a water footprint for a range of feedstocks and conversion pathways, including conventional fuel (corn ethanol, soybean biodiesel, rape seed biodiesel, sugar cane ethanol, molasses ethanol), cellulosic fuel (switchgrass and miscanthus ethanol, corn stover ethanol, wheat straw ethanol, sweet sorghum ethanol, forest wood-based mixed alcohol), and advanced fuel (algae biodiesel, jatropha biodiesel and jet fuel, soybean jet fuel, rapeseed jet fuel) during 2012-2013 (Fig. 1). In the past few years, the trend has been to move toward geospatial analysis in water footprint accounting for biofuels. To address regionspecific water issues, researchers have focused on developing a fine-resolution water footprint for biofuel pathways at the multi-state (regional), state, and county scales. As a result, we have seen an increasing number of publications addressing the water footprint of cellulosic and advanced feedstocks in various regions in the United States and around the world. The type of water use studied has also been expanded from process and irrigation water withdrawal to consumptive blue water use (irrigation water consumed through evapotranspiration) and green water (rain fall consumed through crop evapotranspiration (ET)) in the feedstock growing stage. The expansion of research reflects an elevation of water analysis from an individual constituent-based approach to a holistic approach in which major inputs of the hydrologic cycle are incorporated. In addition, life-cycle analysis methodology on biorefinery co-product credit is adopted to account for water credit. Results from these studies provide valuable regional information and therefore can support water resource planning for 
Fig. 1 Water footprint of various feedstocks and production pathways for biofuels from this review and previous major studies, in liters of water consumption per liter of biofuel produced: (a) blue water footprint, (b) green water footprint $[1,7,8 \cdot \bullet, 9 \bullet, 10-18,24$, $36-38,39 \bullet, 41 \bullet]$. Note that as little as 10 liters of green water or less could be required to produce a liter of biofuel in areas with limited rainfall for certain feedstocks
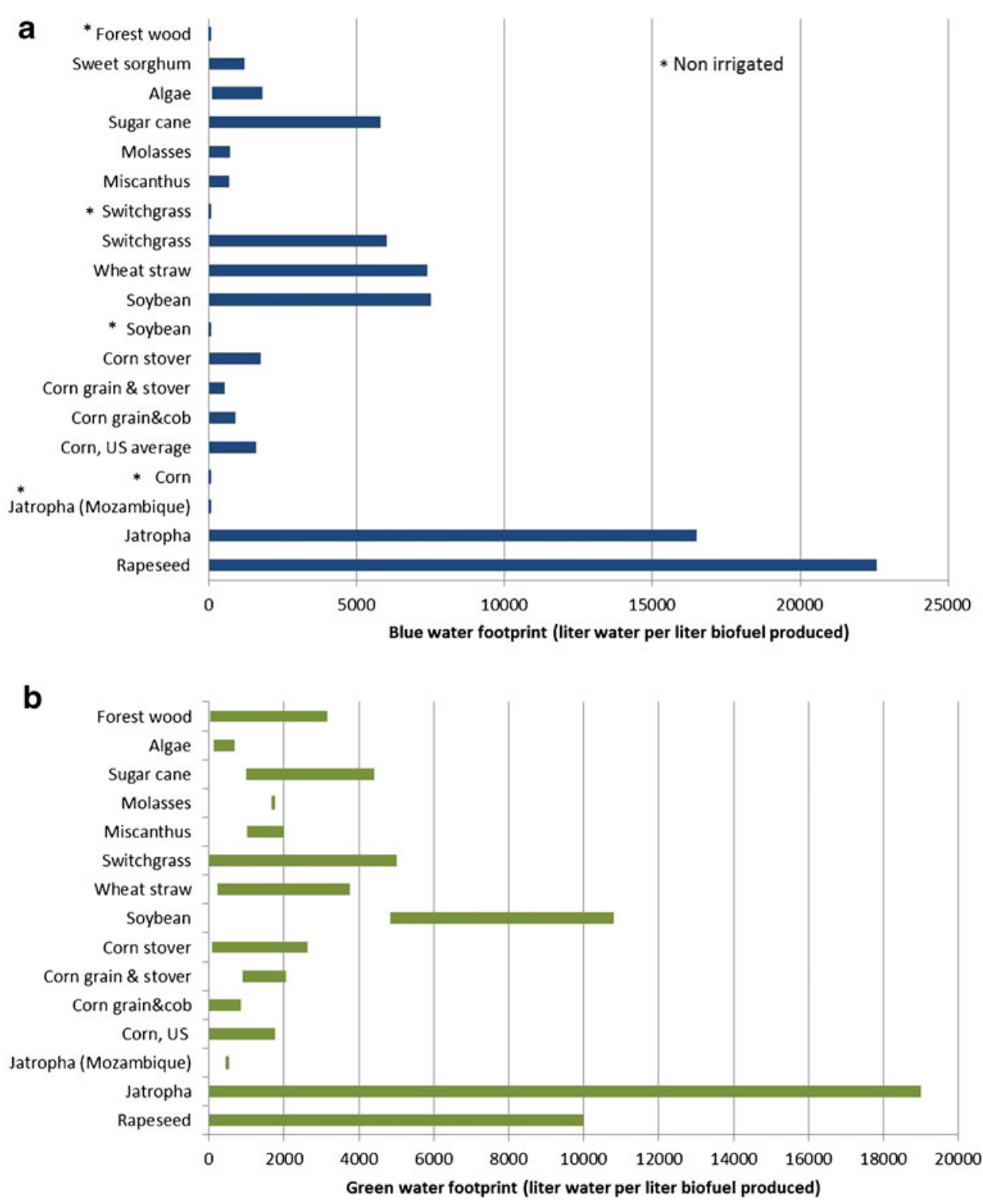

sustainable biofuel feedstock production and refinery site selection, which enables policy makers and industry to make informed decisions. A summary of the blue and green water footprint analysis is presented in Fig. 1.

The water footprint highlights the extensive geographic differences [1, 6, 7, 8••, 9•, 10-18, 24, 36-38, 39•, 40, 41•], which are reflected in particular by the green water footprint. Producing a unit of biofuel from the same feedstock in different regions with variable climate conditions could result in significant differences in the makeup of the water footprint. Figure 1 indicates that green water of as little as 10 liters or lower could be required to produce a liter of biofuel in areas with limited rainfall for certain feedstocks. The remaining water requirements would likely be met through irrigation. As shown by GAEZ simulation, irrigated jatropha grown in the United States would require significantly more blue water than would jatropha grown in Mozambique [12, 18] (Fig. 1), where the climate and humidity are favorable for jatropha, which is drought tolerant [42]. In contrast, the blue water needs of algae grown in the United States and Thailand are similar. Irrigation continues to be the major contributor to the blue water footprint. For example, even though corn needs considerable irrigation when grown in certain regions of the United States, more than $90 \%$ of corn is produced in midwestern states, where irrigation is minimal [41•]. According to a majority of the studies conducted in the past 10 years, the national water footprint of corn is consistently low to modest (Fig. 1). Despite an increase in ET requirement per acre of land for switchgrass, miscanthus, and forest wood [13], because of limited irrigation requirements, biofuels generated from these feedstocks have the lowest blue water footprint per volume of fuel produced compared with biofuels produced from other feedstocks [9•]. 
Historically, analyses of the biofuel grey water footprint have been limited. Published work has typically been limited to national-scale assessment, which does not consider regional variability in contaminant leaching rates and loadings. Recent studies have been performed to estimate the county-level nitrogen grey water footprint for biofuels produced from corn stover, wheat straw, algae, and forest wood resources for the entire United States, and these studies filled a critical gap in biofuel water analysis $[7,8 \bullet \bullet, 9 \bullet]$. Biofuel produced from forest wood resources in the southeastern United States via thermochemical conversion was demonstrated to be one of the most water efficient pathways, not only because of its lower blue water consumption, but also because of its exceptionally low grey water consumption-about $25 \mathrm{~L}$ of grey water per liter of fuel produced, on average. The grey water footprint is sensitive to fertilizer input rate and regional hydrology [7, 9॰].

\section{b Alternative water resource}

Researchers have been actively searching for alternative water resources, primarily because of concerns about the high water demand for algae-based biofuel production [15]. As an infrastructure-compatible drop-in fuel, the production of algae should not compete with food production and should be costeffective, thus inexpensive sources of nutrients and water must be used. Investigations are aimed at determining the feasibility of using municipal wastewater (MWW) treatment plant effluent, saline water, seawater, and dairy wastewater as water resources or as water and nutrient sources $[10,11,16$, 43-45]. Dairy wastewater and MWW are able to provide sufficient nutrients (nitrogen and phosphorus) for algae growth $[43,44]$. Coupling biofuels production with municipal wastewater treatment makes sense because it represents nutrient and water reuse and potentially offers considerable energy savings for a wastewater treatment facility. However, there is a substantial spatial and temporal mismatch between the water requirements of algae growth and the availability of MWW treatment plant effluent in the southern 17 states in the USA [10], which would be a critical factor affecting the degree of freshwater substitution for cultivating algae [10]. By using spatially and temporally available MWW as a sole source of water, 8.6 billion liters of bio-oil can be produced annually with a freshwater blue water footprint that is almost nil [10]. A GIS-based algae cost model has been employed to select alternative water resources, such as saline water and seawater, on the basis of the cost of water delivery in southern states [26]. The Gulf of Mexico and the Florida peninsula appear to be the most favorable regions for growing algae because evaporation rates in these regions are relatively low, which reduces water demand for plant operation and thereby lowers the cost of water delivery [26]. Techno-economic analysis further indicated that when brackish and saline water are adopted as backup water for open pond operation, the consumption of freshwater for the production of algae fuel can be comparable to that of petroleum-derived fuels [16].

\section{Impact of corn stover harvest on water quality and quantity}

Over the past 2 years, researchers have invested considerable effort to understand the impacts of agricultural residue removal on water balance, erosion, and nutrient transport. Sustainable corn stover harvest rate varies with soil and landscape $[46,47]$. The corn stover harvest rate has been simulated under a broad range in the Upper Mississippi River Basin (UMRB) by a number of researchers, from 0 to $25[14,20]$, $38,40,52,70,80$, and up to $100 \%[19,21,25 \cdot]$. The results of SWAT modeling consistently show a decrease in watershed nitrate loading of 2-10\%, a decrease in total phosphorus, and an increase in suspended sediment loss to the watershed under the stover removal scenario, the magnitude of which varies widely with watershed and harvest rate [19-21, 25•] (Table 1).

Cropping system and tillage practices affect the nutrient loadings. Increasing the corn in corn-soybean (CS) rotation or replacing CS rotation with continuous corn would significantly increase nitrate loading to waterways, even in the absence of stover harvest, and decrease soil nitrogen content [25•, 48]. However, under a no-till strategy, the loss of suspended sediments could be minimized to below the baseline, even with $\mathrm{CS}$ rotation. The findings revealed that watershed nutrient and sediment responses are most sensitive to slope, soil type, and fertilizer input rate, and are moderately sensitive to cropping system and other management and practices $[19,20,22,25 \cdot]$. Results also suggest that the rate of supplemental nutrient replacement reported in the literature may be higher than what is required to maintain yield [25•].

When stover is harvested in the UMRB - the major corn production region - US studies agree that streamflow would decrease by $1-3 \%$, along with decreased surface runoff and increased ET [19-22]. Vanloocke and co-workers [14] found that when $25 \%$ of stover is harvested there is a slight, but statistically significant increase (10-20\%) in biomass yieldbased water use efficiency (WUE) for corn. Nevertheless, WUE for corn is consistently lower than that for the perennial grasses miscanthus and switchgrass [14]. The impacts of stover harvest on water quality and water quantity are summarized in Table 1.

\section{Future Land Use Change and Landscape Management}

The concept of landscape management in the context of biofuel production is of interest because of its emphasis on soil conservation and protection of water quality. As representative perennial cellulosic feedstock, switchgrass and hybrid 
Table 1 Watershed responses of various cellulosic feedstock production and climate change scenarios

Nitrogen loss Phosphorus loss Sediment loss Soil water Stream flow Surface runoff ET WUE

\begin{tabular}{|c|c|c|c|c|c|c|c|c|c|}
\hline \multicolumn{10}{|l|}{ 1. Agricultural residue harvest } \\
\hline Stover removal $>24 \%$ & $\downarrow$ & $\downarrow$ & $\uparrow$ & $\downarrow$ & $\downarrow$ & $\downarrow$ & $\uparrow$ & $\uparrow$ & $14,19,20$, \\
\hline $\begin{array}{l}\text { Stover removal with winter } \\
\text { cover crop }\end{array}$ & $\downarrow$ & $\downarrow$ & $\downarrow$ & & & & & $\uparrow$ & 32 \\
\hline Stover removal with no-till & $\downarrow$ & $\downarrow$ & $\downarrow$ & & & & & & 14,21, \\
\hline \multicolumn{10}{|l|}{ 2. Land conversion to perennials } \\
\hline From native grass & $\uparrow$ & & $\downarrow$ & & $\downarrow$ & & & & 14,21 \\
\hline From pasture & $\downarrow$ & $\downarrow$ & $\downarrow$ & & $\downarrow$ & $\downarrow$ & $\uparrow$ & & 20 \\
\hline From row crop & $\downarrow$ & $\downarrow$ & $\downarrow$ & $\downarrow \uparrow \mathrm{a}$ & & & & $\uparrow$ & 31,32 \\
\hline \multicolumn{10}{|l|}{$\begin{array}{l}\text { 3. Mixed feedstock landscape } \\
\text { converted from cropland }\end{array}$} \\
\hline $\begin{array}{l}\text { Agricultural crop dominant with } \\
\text { a fraction of perennial grass }\end{array}$ & $\downarrow$ & $\downarrow \uparrow$ & $\downarrow \uparrow$ & $\downarrow$ & $\downarrow$ & $\downarrow$ & $\uparrow$ & & 20,22 \\
\hline $\begin{array}{l}\text { Perennial grass dominant with } \\
\text { SRWC } \\
\text { 4. Climate changes }\end{array}$ & $\downarrow$ & $\downarrow$ & $\downarrow$ & & $\uparrow \downarrow$ & & $\uparrow \downarrow$ & & 23,32 \\
\hline Increased $\mathrm{CO}_{2}$ & $\uparrow$ & & & $\uparrow$ & $\uparrow$ & & $\downarrow$ & & 27,28 \\
\hline Increased ozone & & & & & & & & $\uparrow$ & 52 \\
\hline $\begin{array}{l}\text { Increased temperature and } \\
\text { decreased precipitation }\end{array}$ & $\downarrow b$ & & & $\downarrow$ & $\downarrow$ & & $\uparrow$ & & 27 \\
\hline
\end{tabular}

${ }^{\text {a }}$ Decreased in summer and increased in spring

${ }^{\mathrm{b}}$ Nitrogen concentration in the stream increases

$\mathrm{SRWC}=$ short rotation woody crop

poplar trees have long been demonstrated as effective conservation options for soil loss control and nutrient mitigation. Inherently, switchgrass and miscanthus exhibit higher WUE than corn $[14,32 \cdot \bullet]$, and their ETs would decrease in response to drought [49]. Various LUC scenarios have been simulated to evaluate the implications of land conversion to single perennial feedstock or a mixed feedstock landscape on water quality and water quantity (Table 1).

Change in water loss is land-cover dependent. Historical data revealed that the conversion of native grassland to the current corn cropping system had a positive effect on the hydrologic cycle - base flow increased in $58 \%$ of corn growing watersheds and streamflow increased significantly in $35 \%$ of the watersheds [50]. When an annual crop is converted to grow switchgrass in the midwestern US regions, assessments projected that ET is likely to increase by $1-2 \%$, soil moisture is likely to decrease by $2 \%$, surface flow runoff decreases, and flow-to-stream discharge decreases by $2-5 \%$ under varying levels of land conversion [20, 21]. These LUC-related water losses could be minimized by implementing double cropping $[32 \bullet \bullet$. Conversely, water withdrawal for the irrigation of feedstock that is associated with LUC may decrease. Taheripour et al. [30] projected a trend toward stronger rainfed land expansion in more carbon-rich environments, and so there would be less irrigation in the future.
Meanwhile, research also showed that changes in hydrology are region-dependent. When replacing a crop with a short rotation woody crop (SRWC) or perennial grasses in a southeastern (US) watershed, Bosch et al. [23] estimated a decrease in ET by $6-19 \%$ and an increase in streamflow by $12-36 \%$, an increase in shallow groundwater flow, and a change in seasonal stream flow patterns - increased flow in winter and less flow throughout the summer.

From a water quality perspective, there are substantial benefits in LUC from annual crops to perennials in low productivity land. Growing perennial grasses reduces nutrient and sediment loss compared with a corn-soybean cropping system [20, 21, $32 \bullet \cdot$; when an annual row crop is converted to SRWC or highyield perennial crops, watershed suspended sediments could decrease by up to $95 \%$ in the southeast coastal plain [23]. Similar results and a 2-4-fold reduction in nitrate loading were obtained by implementing a double-cropping system and riparian buffer in a CS-dominant area in Michigan [32••].

Converting pastureland to switchgrass could result in a slight decrease in nitrate [20]; converting native grassland to perennials could result in an increase in nitrate [21]. Under a future scenario [51] with increased crop yield and a small fraction of switchgrass, responses in water quality appear mixed - positive for nitrate loading, but negative for total phosphorus and suspended sediments [22]. Suitable areas to 
grow perennial grass can be identified by using nitrogen loading and economics as guidelines [48].

\section{Climate Change Impact}

An increase in $\mathrm{CO}_{2}$ concentration in the air could significantly change the hydrology in a region, which further affects crop growth and the water footprint of biofuels. During the period of 1986-2008, an increase of about $1-4 \%$ in streamflow could be attributed to the elevated $\mathrm{CO}_{2}$ in the UMRB [28•]. Doubling air $\mathrm{CO}_{2}$ concentration could lead to a $3 \%$ decline in ET, a $26 \%$ increase in soil moisture, a $67 \%$ increase in ground water recharge, and a $40 \%$ increase in nitrogen loading in the James River Basin in South Dakota [27].

When a climate change scenario is applied, the UMRB will experience a rise in water yield and stream flow in the spring and a decline in the summer with higher variability, which may increase the risk of both flooding and drought [28•]. In addition, rising atmospheric ozone concentration is believed to alter the canopy energy fluxes and have a negative effect on crop productivity [52]. While climate change would directly impact water quality and water use, the reverse is also true [31]. Growing switchgrass in 15-30\% of cropland in Kansas and Oklahoma would result in lower temperatures and slightly higher relative humidity in the spring and slightly lower relative humidity and the depletion of soil moisture in summer [31].

\section{Limitations and Uncertainties}

An important factor in LCA methodology is co-product allocation in a biorefinery, which can significantly affect the outcomes of the analysis. In the studies reviewed, we noticed that different co-product allocation methods have been applied - for example, mass-based, system expansion, or market value methods. Estimating the blue water footprint on the basis of market value tends to yield a higher blue water footprint for a relatively dry region, where irrigation is required. Other studies did not have co-product treatment. These differences could mask some of the results and make detailed

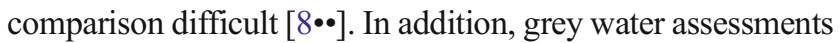
in particular for biorefineries are scarce. The few studies that did address grey water are limited to nitrogen and phosphorus. Grey water assessment of new feedstock relies on experimental testing or pilot/large-scale data, for which the data are mostly not available at this time. Competing water use in a region could also alter the availability of water resources [53]. Climate change and extreme weather have been an increasingly major concern, especially as these parameters relate to the hydrologic cycle. How and to what extent current results of life-cycle water consumption can change under the climate change scenario remains less understood.
There are limitations associated with crop modeling using SWAT. Alamo is currently the only species of switchgrass contained in the SWAT database. Other species and energy crops need to be added to the database. The values of radiation use efficiency (RUE), maximum leaf area index (LAI), and light extinction coefficient $(\mathrm{k})$ are fixed throughout the simulation period. In reality, these parameters can vary considerably, depending on climatic conditions. In addition, SWAT assumes that annuals and perennials reach their full maturity within a single year. While the assumption holds true for annuals, perennials such as switchgrass may take $2-3$ years to reach full growth potential. During the establishment phase, nutrient uptake by the plant will be much less than in the mature phase. Further, the stover removal scenario was represented in previous SWAT modeling as a biomass harvest after a grain-only harvest operation. Whether the mechanism and temporal distribution of nutrient release during the off-season is captured in the model is less clear.

\section{Conclusion}

Significant progress has been made in assessing life-cycle water consumption for conventional, cellulosic, and advanced biofuels. Cellulosic feedstock continues to dominate the analysis of life-cycle water consumption and shows a promising blue and grey water footprint. Alternative water resources have been evaluated for algae production. Transportation of the alternative water remains a challenge in terms of infrastructure and production economics. The most noticeable improvement in the analysis of life-cycle water consumption is the adoption of geospatial analysis to generate a spatially explicit water footprint at a finer scale (i.e., multi-state region, state, county scales) - such studies provide needed information and details to advance our understanding of the interactions among feedstock type, land use change, geographic location, climate, and the total production potential. Watershed modeling coupled with multiple tools/models is able to examine the impact of future production scenarios and climate change on water quality from economic, policy, and environment conservation perspectives at the watershed or river-basin scales. This rigorous modeling simulates the necessary nutrient loadings that enhance estimates of the grey water footprint. This trend is likely to continue. Future analysis of life-cycle water consumption would address water consumption issues at spatial resolution for both feedstock and biorefineries, with an emphasis on alternative water resources, grey water footprint, consistent co-product allocation methodology, new feedstock/technology water footprint development, and potentially a dynamic life-cycle water footprint incorporating changes in land use and climate. 
Acknowledgements This work is supported by the U.S. Department of Energy, Office of Energy Efficiency and Renewable Energy, Bioenergy Technologies Office, under contract \# DE-AC0206CH11357.

Conflict of Interest M. Wu declares no conflicts of interest.

Z. Zhang declares no conflicts of interest.

Y. Chiu declares no conflicts of interest.

Human and Animal Rights and Informed Consent This article does not contain any studies with human or animal subjects performed by any of the authors.

\section{References}

Papers of particular interest, published recently, have been highlighted as:

- Of importance

•- Of major importance

1. Gheewala SH, Silalertruksa T, Nilsalab P, Mungkung R, Perret SR, Chaiyawannakarn N. Implications of the biofuels policy mandate in Thailand on water: The case of bioethanol. Bioresour Technol. 2013;150:457-65.

2. Islam S. Implications of biofuel policies for water management in India. International Journal of Water Resources Development. 2012;28(4):601-13.

3. Oehlschlaeger MAH, Sexton MN. Prospects for biofuels: A review, Journal of Thermal Science and Engineering Applications. 2013;5(2), Article number: 021006.

4. Fontaras G, Skoulou V, Zanakis G, Zabaniotou A, Samaras Z. Integrated environmental assessment of energy crops for biofuel and energy production in Greece. Renew Energy. 2012;43: 201-9.

5. Chanakya HN, Mahapatra DM, Ravi S, Chauhan VS, Abitha R. Sustainability of large-scale algal biofuel production in India. Journal of Indian Institute of Science. 2012;92(1):63-98.

6. Nunez M, Pfister S, Anton A, Munoz P, Hellweg S, Koehler A, et al. Assessing the environmental impact of water consumption by energy crops grown in Spain. J Ind Ecology. 2013;17(1):90-102.

7. Chiu Y, Wu M. Assessing county-level water footprints of different cellulosic-biofuel feedstock pathways. Environ Sci Technol. 2012;46:9155-62.

8.• Wu M, Chiu Y, Demissie Y. Quantifying the regional water footprint of biofuel production by incorporating hydrologic modeling. Water Resource Research. 2012;48(10):W10518. Excellent review of major life-cycle water footprint assessments for biofuels. Analysis demonstrated that system boundary and water allocation are key to consistent water footprint accounting. Study improved life-cycle water consumption analysis by watershed modeling and satellite data verification.

9. Chiu Y, Wu M. Water footprint of biofuel produced from forest wood residue via a mixed alcohol gasification process. Environ. Res. Lett. 2013;8(3). Good study illustrating variability of life-cycle water consumption of wood-based biofuel in two different feedstock logistic systems and feedstock mix in the southeastern US. Analysis reveals low blue and grey water requirements for the forest woodderived biofuels.

10. Chiu Y-W, Wu M. Considering water availability and wastewater resources in the development of algal bio-oil. BioFPR. 2013;7(4): 406-415. July/Aug.
11. Venteris ER, Skaggs RL, Coleman AM, Wigmosta MS. A GIS cost model to assess the availability of freshwater, seawater, and saline groundwater for algal biofuel production in the United States. ES\&T. 2013;47(9):4840-9.

12. Hagman J, Nerentorp M, Arvidsson R, Molander S. Do biofuels require more water than do fossil fuels? Life cycle-based assessment of jetropha oil production in rural Mozambique. J Clean Prod. 2013;53:176-85.

13. Zhuang Q, Qin Z, Chen M. Biofuel, land and water: Maize, switchgrass or miscanthus? ERL. 2013;8(1) 015020:1-6.

14. VanLoocke A, Twine TE, Zeri M, Bernacchi CJ. A regional comparison of water use efficiency for miscanthus, switchgrass and maize. Agric For Meteorol. 2012;164:82-95.

15. Beal CM, Hebner RE, Webber ME, Ruoff RS, Seibert AF, King CW. Comprehensive evaluation of algal biofuel production: Experimental and target results. Energies. 2012;5(6):1943-81.

16. Vasudevan V, Stratton RW, Pearlson MN, Jersey GR, Beyene AG, Weissman JC, et al. Environmental performance of algal biofuel technology options. ES\&T. 2012;46(4):2451-9.

17. Ceclan RE, Pop A, Ceclan M. Studies concerning the integrated use of sweet sorghum for bioethanol production in Romania. Chem Eng Trans. 2012;29:877-82.

18. Staples MD, Olcay H, Malina R, Trivedi P, Pearlson MN, Strzepek $\mathrm{K}$, et al. Water consumption footprint and land requirements of large-scale alternative diesel and jet fuel production. ES\&T. 2013. doi:10.1021/es4030782.

19. Cibin R, Chaubey I, Engel B. Simulated watershed scale impacts of corn stover removal for biofuel on hydrology and water quality. Hydrological processes. 2012;26(11):1629-41.

20. Wu M, Demissie Y, Yan E. Simulated impact of future biofuel production on water quality and water cycle dynamics in the UMRB. Biomass Bioenergy. 2012;41:44-56.

21. $\mathrm{Wu} \mathrm{Y,} \mathrm{Liu} \mathrm{S.} \mathrm{Impacts} \mathrm{of} \mathrm{biofuels} \mathrm{production} \mathrm{alternatives} \mathrm{on} \mathrm{water}$ quantity and quality in the Iowa River Basin. Biomass Bioenergy. 2012;36:182-91.

22. Demissie $\mathrm{Y}$, Yan E, Wu M. Assessing regional hydrology and water quality implications of large-scale biofuel feedstock production in the Upper Mississippi River Basin. ES\&T. 2012;46(16):9174-82.

23. Bosch DD, Arnold JG, Kiniry JR, Vellidis G, Srivastava P. Watershed-scale impact of land use changes for bioenergy production. ASABE-21st century Watershed Technology Conference and Workshop 2012: Improve Water Quality and Environment. May 27-June 1, 2012, pp. 89-96.

24. Dalla Marta A, Mancini M, Natali F, Orlando F, Orlandini S. From water to bioethanol: The impact of climate variability on the water footprint. Journal of Hydrology. 2012;444-445:180-186, June 11.

25. Gramig BM, Reeling CJ, Cibin R, Chaubey I. Environmental and economic trade-offs in a watershed when using corn stover as bioenergy. ES\&T. 2013;47(4):1784-91. Good study demonstrating a method to select crop residue harvest operation based on economic and water quality criteria, determined from field testing data.

26. Einheuser MD, Nejadhashemi AP. Woznicki SA. Biomass and Bioenergy: Simulating stream health sensitivity to landscape change due to bioenergy crops expansion; 2013. doi:10.1016/j.biombioe. 2013.08.025.

27. Wu Y, Liu S, Gallant AL. Predicting impacts of increased $\mathrm{CO} 2$ and climate change on the water cycle and water quality in the semiarid James River Basin of the Midwestern USA. Sci Total Environ. 2012;430:150-80

28. Wu Y, Liu S, Abdul-Aziz OI. Hydrological effects of the increased $\mathrm{CO} 2$ and climate change in the UMRB using a modified SWAT. Climate Change. 2012;110:977-1003. Good study exploring the effect of increased $\mathrm{CO} 2$ on hydrology and crop water use in biofuel feedstock dominant watersheds, based on historical climate and hydrological data, indicating the potential of climate change on life-cycle water consumption. 
29. Li R, Merchant JW. Modeling vulnerability of groundwater to pollution under future scenarios of climate change and biofuelsrelated land use change: A case study in North Dakota. USA Science of the Total Environment. 2013;447:32-45.

30. Taheripour F, Hertel TW, Liu J. The role of irrigation in determining the global land use impacts of biofuels. Energy, Sustainability and Society. 2013;3(1):1-18.

31. Anderson CJ, Anex RP, Arritt RW, Gelder BK, Khanal S, Herzmann DE, et al. Regional climate impacts of a biofuel policy projection. Geophys Res Lett. 2013;40(6):1217-22.

32.• Eranki PL, Manowitz DH, Bals BD, Izaurralde RC, Kim S, Dale $\mathrm{BE}$. The watershed scale optimized and rearranged landscape design (WORLD) model and local biomass processing depots for sustainable biofuel production: Integrated life cycle assessment. BioFBR. 2013;7(5):537-50. Excellent study that demonstrates that the negative effect of increased feedstock production on water quality can be minimized economically by implementing a mixed feedstock, including crop residue and perennial grasses under BMPs and a double-cropping system.

33. Bernardi A, Giarola S, Bezzo F. Optimizing the economics and the carbon and water footprints of bioethanol supply chains. BioFPR. 2012;6(6):656-72.

34. Yang Y. Life cycle freshwater ecotoxicity, human health cancer, and noncancer impacts of corn ethanol and gasoline in the U.S. J of Cleaner Production. 2013;53:149-57.

35. Chiu Y-W, Suh S, Pfister S, Hellweg S, Koehler A. Measuring ecological impact of water consumption by bioethanol using life cycle impact assessment. Int J Life Cycle Assess. 2012;17:16-24.

36. King CW, Webber ME. Water intensity of transportation. Environ Sci Technol. 2008;42(21):7866-72.

37. Gerbens-Leenes PW, Hoekstra AY, van der Meer TH. The water footprint of bioenergy. Proc Natl Acad Sci. 2009;106(25):10219-23.

38. Wu M, Mintz M, Wang M, Arora S. Water consumption in the production of ethanol and petroleum gasoline. Environ Manag. 2009;44:981-97.

39. Mishra GS, Yeh S. Life cycle water consumption and withdrawal requirements of ethanol from corn grain and residues. Environ Sci Technol. 2011;45(10):4563-9. Good study incorporating irrigation technology and water delivery into water footprint accounting.

40. Scown CD, Horvath A, McKone TE. Water footprint of U.S. transportation fuels. Environ Sci Technol. 2011;45(7):2541-53.

41. Wu M, Mintz M, Wang M, Arora S, Chiu Y. Water consumption in the production of bioethanol and petroleum gasoline. ANL/ESD 2011-update. 2011. Argonne National Laboratory, Lemont, IL, USA. Good analysis of process-based water consumption in the use of conventional petroleum and biofuels in major life-cycle stages with recent production datasets.
42. Kesava Rao AVR, Wani SP, Singh P, Srinivas K, Srinivasa Rao C. Water requirement and use by Jatropha curas in a semi-arid tropical location. Biomass Bioenergy. 2012;39:175-81.

43. Kothari R, Pathak V, Kumar V, Singh DP. Experimental study for growth potential of unicellular alga Chlorella pyrenoidosa on dairy wastewater: An integrated approach for treatment and biofuel production. Bioresour Technol. 2012;16:466-70.

44. Anderson V, Broberg S, Hackl R. Integrated algae cultivation for municipal wastewater treatment and biofuels production in industrial clusters. 2012. World Renewable Energy Forum, WREF 2012, World Renewable Energy Congress XII and Colorado Renewable Energy Society Annual Conference. American Solar Energy Society. 2012;1:684-91.

45. Roberts GW, Fortier MP, Sturm BSM, Stagg-Williams SM. Promising pathway for algal biofuels through wastewater cultivation and hydrothermal conversion. Energy and Fuels. 2013;27(2): 857-67.

46. Muth Jr D, Bryden KM. A conceptual evaluation of sustainable variable-rate agricultural residue removal. Jeq. 2012;41:1796-805.

47. Wilhelm WW, Hess JR, Karlen DL, Johnson JMF, Muth D, Baker $\mathrm{JM}$, et al. Balancing limiting factors and economic drivers for sustainable Midwestern US agricultural residue feedstock supplies. Industrial Biotechnol. 2010;6(5):271-87.

48. $\mathrm{Wu} \mathrm{Y,} \mathrm{Liu} \mathrm{S,} \mathrm{Li} \mathrm{Z.} \mathrm{Identifying} \mathrm{potential} \mathrm{areas} \mathrm{for} \mathrm{biofuel} \mathrm{production}$ and evaluating the environmental effects: a case study of the James River Basin in the Midwestern U.S. GCB Bioenergy. 2012;4:87588.

49. Wagle P, Kakani VG. Growing season variability in ET, ecosystem water use efficiency, and energy npartitioning in switchgrass. Ecohydrology. 2012. doi:10.1002/eco.1322.

50. Xu X, Scanlon BR, Schilling K, Sun A. Relative importance of climate and land surface changes on hydrologic changes in the US Midwest since the 1930s: Implications for biofuel production. J Hydrol. 2013;497:110-20.

51. U.S. Department of Energy. U.S. Billion-Ton Update: Biomass supply for a bioenergy and bioproducts industry. RD Perlack, BJ Stokes (Leads). ORNL/TM-2011/224. 2011. Oak Ridge National Laboratory, Oak Ridge, TN. 227 p.

52. Vanloocke A, Betzelberger AM, Ainsworth EA, Bernacchi CJ. Rising ozone concentrations decrease soybean evapotranspiration and water use efficiency whilst increasing canopy temperature. New Phytol. 2012;195:164-71.

53. Thomson B. Energy, water and arid southwest: resources and challenges. Proceedings of the 2012 Congress, World Environmental and Water Resources Congress 2012: Crossing Boundaries. P2803-2813. Environ. Water. Res. Ins. ASCE. May 20-24. 